\title{
A EDUCAÇÃO NA ENCRUZILHADA DAS POLÍTICAS PÚBLICAS NA AMÉRICA LATINA
}

\author{
La educación en la encrucijada de las políticas públicas en América Latina
}

Education at the crossroads of public policies in Latin America

Agustín Villarreal*

https://doi.org/10.38117/2675-181X.formov2020.v2i2n4.556-574

\section{RESUMO}

O artigo é produto dos diálogos no marco temático denominado "Educação e políticas públicas dos estados latino-americanos nos tempos neoliberais; proteções e desproteções" apresentado em universidades e países latino-americanos. O objetivo é problematizar o impacto das políticas públicas por meio do conceito de educação em uma encruzilhada, para possibilitar a revisão de reformas educacionais, significados, linhas de pesquisa e da consciência humanística dos educadores. As análises foram realizadas a partir de uma pesquisa exploratória, de caráter qualitativo, por meio da coleta de dados através de debates, grupos de discussão e mesas redondas. As análises do trabalho são realizadas usando a técnica de análise de conteúdo, que inclui exposições, citações relevantes e intervenções. Como resultados, destaca-se que o político está relacionado ao público e à educação, mas que a complexidade do campo educacional e as distânciasobjetividades do educador devem ser elucidadas.

PALAVRAS CHAVE: Educação na encruzilhada; Reformas educacionais; Estado capitalista; Proteções e desproteções.

\section{RESUMEN}

El artículo es producto de los diálogos en el marco temático denominado: "La educación y las políticas públicas de los estados latinoamericanos en tiempos neoliberales: protecciones y desprotecciones" presentado en universidades y países latinoamericanos. El objetivo fue problematizar el impacto de las políticas públicas por medio del concepto de educación en encrucijada que posibilito revisar las reformas educativas, sentidos, líneas de investigación y la conciencia humanística de los educadores. Los análisis fueron realizados con un tipo de investigación exploratoria con un carácter cualitativo mediante la recopilación de datos por medio de conversatorios, grupos de discusión, y mesas redondas. Los análisis del trabajo se realizan mediante la técnica de análisis de contenido que contemplan 
exposiciones, citas de relevancia, e intervenciones. Como resultado, se destaca que lo político está relacionado con lo público y educativo pero que se debería poder dilucidar la complejidad del campo educativo y las distancias-objetividades del educador.

PALABRAS CLAVE: La educación en la encrucijada; Reformas educativas; Estado Capitalista; Protecciones y desprotecciones.

\begin{abstract}
This article is a product of dialogues in the framework called: "Education and public policies of Latin American states in neoliberal times: protections and unprotections", presented in universities in Latin American countries. The objective was to problematize the impact of public policies through the concept of education at a crossroads that invites us to review educational reforms, meanings, research lines and the humanistic consciousness of educators. The analyses were carried out from exploratory research with qualitative profile by means of data collection through conversations, discussion groups, and round tables. The analyses of the work are carried out using the content analysis technique that includes exhibitions, relevant citation, and interventions. As results, it is remarkable that the political is related to the public and educational but that the complexity of the educational field and the distances-objectivities of the educator should be elucidated.
\end{abstract}

KEYWORDS: Education at the crossroads; Educational reforms; Capitalist State; Protections and unprotections.

\title{
Introdução
}

O material para esta análise decorre de diferentes reuniões técnicas, referente a um painel de especialistas e grupos de trabalho com agentes que ocupam diversas posições no campo educacional da América Latina e discutem a relação entre "Educação e políticas públicas dos Estados da América Latina. em tempos neoliberais, proteções e desproteções". O artigo pretende mapear as discussões que ocorreram na Faculdade de Ciências Sociais da América Latina (FLACSO), sede da cidade de Quito - Equador; na sede da FLACSO, em Assunção - Paraguai; e na Universidade de Manizales, na cidade de Manizales - Colômbia, no âmbito da II Bienal de Infâncias e Jovens.

Inicialmente, o cerne do texto será o conceito de "educação na encruzilhada" (MARITAIN, 2008), citado pelo Professor Domingo Rivarola, da sede da FLACSO, em Assunção (2017), para analisar quais são os sentidos que a educação latino-americana 
precisará rever em tempos de crise institucional. Nesta perspectiva tomamos para a análise o conceito de "educação na encruzilhada", de Maritain (2008, p. 32), quando afirma que a "[...] pedagogia moderna alcançou um progresso incalculável, enfatizando a necessidade de analisá-la cuidadosamente e estabelecer sua meta no tema humano". É, assim, que essa categoria analítica nos permite entender os objetivos, fins ou sentidos da educação nos diferentes contextos socioculturais, que atravessam os sistemas educacionais latino-americanos. Mas também, é por meio dela que compreendemos os desafios a serem enfrentados como agentes educacionais contemporâneos, com consciência humanística. Consideramos, ainda, que os pontos principais dessa crise institucional se devem ao esquecimento da competência teórica e reflexiva e à necessidade de que a educação seja valorizada para além da transmissão de competências técnicas e políticas. Além disso, é preciso reconhecer o debate em relação ao desenvolvimento da técnica, que é acentuado como objetivo central da instituição-escola, considerando que a escola é o centro dos debates contemporâneos pedagógicos e políticos.

Ao longo do texto, a ideia de política pública está subjacente ao conceito de Kraft e Furlong (2006, p. 5), que sustentam que "é um curso de ação ou inação do governo em resposta a problemas públicos". A essa definição, é preciso adicionar que a política pública é uma ação organizada, "[...] que visa atingir objetivos de interesse comum [...]" (OCAMPO, 2004, p.171). Por esse motivo, os grupos analisados discutiram a respeito de ações e programas específicos enquadrados na análise de políticas educacionais. Consideramos, assim, que o estudo das políticas educacionais como políticas públicas e políticas sociais implica posicionar a análise dos fenômenos de poder, que se desdobram na sociedade em cada contexto econômico, político, social, jurídico e cultural (FELDFEBER, 2014). Em resumo: pretendemos analisar as discussões desenvolvidas pelas conferências selecionadas para este estudo, que tratam de ações, programas ou projetos em contextos específicos da América Latina.

O tipo de pesquisa é exploratório (SAMPIERI HERNÁNDEZ et al., 2010), porque este texto tem como objetivo destacar ou desvendar as principais propostas e caminhos que a educação está percorrendo, nos diferentes países da América Latina, por meio das vozes dos palestrantes (incluindo o autor). Não há uma análise aprofundada de muitas das expressões apresentadas ou uma comparação entre políticas públicas e educacionais entre diferentes países. Ao contrário, procura-se identificar as relações das políticas educacionais a partir de reformas educacionais, linhas de pesquisa e propostas pedagógicas relacionadas ao estado capitalista (DANANI, 1996). Colocam-se, em tensão, os diálogos mais relevantes quanto ao conceito de "educação em uma encruzilhada" (MARITAIN, 2008) e o compromisso com a educação (FERNANDEZ ENGUITA, 2016). Menciona-se que a metodologia é de natureza qualitativa, a fim de realizar uma análise de conteúdo (GOMEZ MENDOZA, 2000) das expressões e citações mais 
relevantes dos palestrantes que participaram desse quadro temático. A coleta de dados é instrumentalizada por meio de mesas redondas, grupo de discussão e pelo método Delphi (ANDER EGG, 1995), na modalidade chamada de discussão, utilizada em países como: Equador, Colômbia e Venezuela.

A amostra é de um tipo não probabilístico, argumentando que "uma amostra não é probabilística quando não sabemos a probabilidade de seleção de um elemento na amostra [...], sua seleção será uma operação arbitrária, sem um instrumento de ordem estatística que indique o tamanho exato da amostra" (VIEYTES, 2004, p. 399). Assim, os participantes dos grupos estavam inscritos na proposta temática denominada "Educação e políticas públicas dos estados latino-americanos em tempos neoliberais: proteções e desproteções". Por esse motivo, os atores compartilham a mesma preocupação e a amostra é enquadrada na forma mais comum de pesquisa qualitativa denominada "amostragem por objetivo", em que os participantes escolhem o eixo temático em casos de divulgação científica, como congressos, palestras e conferências. Diante disso, as apresentações mais pertinentes são selecionadas para as categorias de análise.

Muitos dos participantes dos diferentes países, especialmente, em relação ao material de leitura dos trabalhos e das discussões, concordam com a visão crítica de Danani (1996, p. 18), quando afirma que: "o debate sobre o público é o debate sobre a política". Nesse sentido, deve-se refletir sobre o marco das políticas educacionais, que surgem, continuam e são interrompidas, de acordo com o contexto socioeconômico em que cada país está inserido e com os programas educacionais propostos por seus governos de plantão. Dessa forma, em termos de Danani (1996), as políticas públicas podem ser protecionistas ou desprotecionistas, porque o Estado está tingido de relações capitalistas de produção, que o definem como um estado capitalista. O que nos leva a pensar que uma política social ou educacional está ligada a uma proteção ou falta de proteção contra o estado capitalista, que criou uma ruptura entre capital e trabalho; ou seja, relações de exploração versus salário.

Ao final do texto, desenvolvemos a proposta de Paugam (2010), na qual o autor propõe realizar uma análise situacional de pesquisadores, técnicos e responsáveis pela produção de ciências no campo da gestão ou direção das políticas pedagógicas. Assim, também é mencionado o campo político (BOURDIEU, 2001) e as distâncias relativas, que devem ser consideradas para se ter uma posição objetiva na hora de tomar decisões. É, aqui, que são propostas algumas alternativas, que reivindicam a posição do educador como ator ativo e reflexivo, capaz de realizar ciência da educação na vida cotidiana, tomando, como exemplo, o que é comumente exaltado no ensino superior na Argentina, como "el docente investigador". 
Embora várias linhas tenham sido levantadas durante o desenvolvimento dos diferentes grupos e pesquisadores, consideramos importante retornar a esses conceitos para focalizar a análise e reflexão da educação latino-americana e de suas principais práticas educacionais. E, nesta direção, a figura do professor, como agente social, é um dos pontos de análise, uma vez que muitas das discussões se concentram em sua ação; além disso, destacamos o papel da escola em relação às decisões políticas e do Estado.

\section{Ponto de partida: "Vamos concordar em alguns pontos"}

Discutir os sentidos da educação e sua relação com as políticas públicas em um contexto neoliberal nos obriga a pensar sobre o seu papel e o papel do Estado em nossas sociedades. E, nesta perspectiva, a definição de Oscar Oszlak (1982) será usada, entendendo o Estado como um conjunto de relações sociais estruturadas em um aparato institucional, conforme anuncia o autor:

[...] um processo de construção social no qual se definem diferentes planos e componentes que estruturam a vida social organizada. Em conjunto, esses planos formam certa ordem, cuja especificidade depende de circunstâncias históricas complexas. Elementos tão variados quanto o desenvolvimento relativo das forças produtivas, os recursos naturais disponíveis, o tipo de relações de produção estabelecidas, a estrutura de classe resultante ou a inserção da sociedade no enredo das relações econômicas internacionais contribuem em graus variados para sua conformação. (OSZLAK, 1982, p.27) ${ }^{1}$

Também, será usado o conceito de Estela Grassi (2008, p. 20-22), que entende o Estado como aquele dispositivo que "[...] expressa e produz uma ordem quando ativadas políticas voltadas à consolidação de um projeto hegemônico; isto é, uma ordem políticosocial que, por definição, é transitória, mas não indeterminada”. As políticas ativas do Estado são, como diz Sousa Santos (1998), “intervenções estatais" no Estado, e que, segundo Grassi (2008, p. 12-13), “[...] transformam simultaneamente a capacidade de intervenção do Estado posteriormente". Essa definição apoia, principalmente, a importância do conceito de reprodução social, que abordaremos como "o amplo senso de recreação do reconhecimento das diretrizes básicas que norteiam a vida social e a consequente continuidade elementar das práticas sociais" (GIDDENS, 1995, p. 66-67). Além disso, é preciso considerar o pensamento de Grassi (2008), quando ressalta que o processo de incorporação em um estado é restrito, especificamente, à reprodução da vida e da força de trabalho.

\footnotetext{
${ }^{1}$ Tradução própria do espanhol.
} 
Essa concepção oferece a possibilidade de observar o Estado como um conjunto de relações, em que todos os atores sociais estão envolvidos, contradizendo a posição de alguns professores ou técnicos, que, nos depoimentos coletados, identificam o Estado como uma instituição externa e alheia a seus relacionamentos, confundindo-se, em alguns casos, com o governo.

No entanto, existem pontos de encontro entre a maioria dos atores presentes na discussão sobre políticas sociais e suas intervenções, uma vez que compartilham a ideia, proposta por Danani e Hintze (2011, p.13), de que "o Estado deve proteger relações estabelecidas com o mercado de trabalho". Os autores refletem sobre a "capacidade de proteção social em geral para se referir ao escopo quantitativo e qualitativo da satisfação de necessidades que adquirem os benefícios e serviços definidos no interior de um determinado setor político (que neste caso é o da previdência social)" (DANINI; HINTZE, 2011, p. 85).

Nesta perspectiva, a concepção de bem-estar e de trabalho e bens de serviços, que devem ser prestados como uma possibilidade real para a reprodução da vida, é apresentada como inseparável, pois é "[...] parte das condições gerais de reprodução da força de trabalho e, portanto, reprodução da vida da população como um todo nas sociedades capitalistas" (DANANI; HINTZE, 2011, p. 13). É essencial observar que os sinônimos são trabalhados como "reprodução da força de trabalho" e "reprodução da vida" (DANANI; HINTZE, 2011, p. 13). Além disso, é importante colocar em pauta o problema apresentado pelo capitalismo financeiro é propor uma ruptura entre capital e trabalho, em que as políticas sociais devem enfatizar a proteção, possibilitando as condições de acesso ao mercado de trabalho. Como afirmam Danani e Hintze (2011, p. 13-14):

A proteção social é um lugar central nas condições gerais de
reprodução: faz parte dos relacionamentos e instituições em que a forma
de mercadoria da força de trabalho toma forma, além de ter um emprego
protegido ou ter um emprego não protegido faz parte desses universos
opostos.

A discussão tomou como tema, por exemplo, a intervenção do Estado em matéria de política protecionista social. No caso da Argentina (1989 - 2003), durante o período neoliberal e de bem-estar social, baseada no desaparecimento do público e na baixa cobertura universal, a política foi estritamente reduzida e com foco somente em ações simples para uma pequena porcentagem de destinatários, como, por exemplo: levar sacos de comida para as salas de jantar, e distribuir alimentos para famílias em extrema pobreza. Na política trabalhista, de 1991, foi aprovada a Lei Nacional do Trabalho (24.013), mas não foi possível prestar apoio no nível formal, produzindo uma flexibilidade e redução no mercado de trabalho, que, após sete anos, gerou milhares de desempregados por falta 
de regulamentação. Dessa forma, a política social da época não se refletia na política trabalhista, nos serviços universais e no bem-estar como um todo, mas em uma política social fragmentada, reduzindo-a a uma assistência isolada e focalizada. Assim, é demonstrado que a política pública da década de 1990, na República Argentina, desarma a política trabalhista planejada, e leva o Estado a reduzir o público como meio de aprofundar as políticas neoliberais. Além da República Argentina, Pablo Gentili (2009) apresenta a perspectiva de que o Estado, na América Latina, é responsável por lutar contra as desigualdades. Isso pode ser compreendido por várias razões, mas talvez uma das mais relevantes seja a que as políticas educacionais implementadas, na década de 1990, tenham alcançado, por um lado, maior cobertura por políticas públicas, como educação básica e obrigatória; e, por outro, produziram novas formas de exclusão desigual e educacional, como "exclusão inclusiva" (GENTILI, 2009, p 30).

Outro exemplo de intervenção do Estado, muito importante para analisar, é apresentado na discussão da sede da Flacso - Equador (27 de outubro de 2017), por Cecília Santana, com base em seu trabalho intitulado "Implementação da política de ensino para o ensino médio no Equador: reforma educacional de 2011 sob o aspecto socioeconômico". Analisando as perspectivas do modelo para o estudo da implementação de políticas de cima para baixo e de baixo para cima (em inglês "top-down" ou "método da raiz”), Ballart e Ramió (2000, p 40) concluem que o governo Rafael Correa (20072017) apresentou desembolsos com margem de erro de $0,1 \%$ de 4,86\% do PIB investido na educação. É importante assinalar, também, que essa metodologia de estudo ajuda a monitorar políticas públicas ou educacionais. Por outro lado, observamos, por exemplo, que o problema surge com a análise do método da raiz, pois a abordagem se refere à natureza ou explicação da política pública; uma vez que não se permite a diferenciação entre implementação e política. Assim, críticas às abordagens heurísticas sugerem que, muitas vezes, esse método não nos possibilita entender os diferentes estágios da implementação política, e não é fornecida uma boa estrutura para observar as mudanças nas políticas ou o processo de aprendizado dessas políticas.

Nesta perspectiva a política de educação analisada encerrou sua etapa, ao iniciar um novo governo no Equador, de modo que a análise não pode ser entendida como política de processo ou processo político, porque os marcos ou projetos políticos tinham outra orientação. As políticas públicas e educacionais precisariam de um segundo momento de análise para entender não apenas o seu ponto inicial e/ou final, mas também compreender como elas se vinculam ao Estado e ao mercado de trabalho, para que não se reproduza uma política com foco na função de uma parte da população, deixando de lado o interesse comum.

Essa apresentação colocou, então, no centro do debate, questões sobre o papel da economia nas políticas públicas, tendo como objetivo o público, em qualquer dimensão 
social e coletiva, sempre oposto ao privado. A discussão do público configura o campo do político, define-se em um discurso - meio simbólico -, que é "produzido e reproduzido" (GRASSI, 2008, p. 34); ou seja, seria como uma diretriz, que é marcada a partir da palavra político, definindo, assim, o público.

Outra apresentação da mesa de trabalho foi sobre "Um olhar sociológico sobre alocação universal de crianças do campo da saúde e educação na República Argentina", de Agustín Villarreal (2016), em que se argumentou que, desde a incorporação da Alocação Universal para o Filho - $\mathrm{AUH}^{2}$, por meio do Decreto 1602/09, sancionado pelo Poder Executivo da Nação Argentina, e que começa a produzir efeitos a partir de $1^{\circ}$ de novembro de 2009, as escolas com os atores / agentes escolares identificam novos processos de socialização, escolaridade e organização, tanto políticas macro educacionais (decisões de gestão, planejamento territorial etc.), quanto micro políticas educacionais (estrutura familiar e desenvolvimento individual).

Os processos de escolarização estão intimamente relacionados à aprendizagem familiar ou à primeira educação. É, aqui, que a AUH está gerando práticas sociais, que configuram um modo de ser na escola e produzem novas representações e discursos diferentes daqueles que estavam sendo produzidos.

O impacto social da AHU apresenta resultados no campo da saúde, educação, economia e política, em que são apresentadas novas possibilidades de análise para esse direito. Explica-se que, centralmente, na educação, a escola é apresentada como um "condicionador / obrigação", para que o beneficiário da AUH possa efetuar a transferência monetária, aproximando os atores educacionais e familiares dos alunos da instituição. Pois, eles geram discursos, práticas e estratégias sociais (BOURDIEU, 1997, p 63-64), gerando, também, uma "batalha cultural" no campo pedagógico e discursivo. Ainda, é preciso mencionar que o trabalho pedagógico racional (BOURDIEU; PASSERON, 1998, p. 25) foi enfatizado, forçando os beneficiários da AUH a "controlar / demonstrar" a assistência da criança ou adolescente à escola, criando novas relações simbólicas, sociais e materiais entre atores/agentes da escola (supervisores, gerentes, professores, alunos, pais, entre outros). O que reconfigura, assim, o espaço social da escola e das famílias beneficiárias (VILLARREAL, 2016, p. 3 - 4).

A partir das duas análises apresentadas acima, observa-se que Estado e política estão ligados no curso de suas ações. Uma premissa usada, nas mesas e nos grupos de discussão, foi que "a discussão do público é a discussão do político" (DANANI; HINTZE, 2011 p. 38). Nota-se, neste sentido, que há uma reflexão sobre o público, pois se trata de

\footnotetext{
${ }^{2}$ Tradução própria do espanhol. As siglas são Asignación Universal por Hijo - AUH- (VILLARREAL, 2016, p. 1-2).
} 
uma avaliação enquadrada historicamente no contexto do político, porque o público é uma construção sócio-histórica. A frase de Danani e Hintze (2011) foi analisada, brevemente, para a intervenção dos participantes, argumentando que essa construção é definida a partir das propostas políticas (como observado no parágrafo anterior contra as privatizações da década de 1990), que revelam uma maneira de fazer política. Um exemplo seria referente aos "trabalhadores desprotegidos e desempregados", nos anos 1990, que, diferentemente da previdência social do período político de 2003-2008, foram intrinsecamente modificados na proteção contra os mais atacados pelo capitalismo estrutural. Para alguns professores e orientandos de Flacso Equador, o Estado, por exemplo, desprotege os povos indígenas, pois este setor deixou de participar das reuniões sindicais dos gabinetes com o governo de Lenin Moreno (27 de outubro de 2017). Um outro caso foi o que também ocorreu nas intervenções sobre a política educacional argentina, em que houve um diálogo sobre os riscos da política social de caráter focalizado e condicionado.

Assim, depois de discutir o Estado, as políticas públicas e seu curso, tendo como slogan "vamos concordar em alguns pontos", é que, nas mesas apresentadas, compreendeu-se o significado da relação político/público. As apresentações foram as mais relacionadas politicamente, desvendando um pouco sobre o que acontece com as políticas educacionais a partir da concepção e adesão às premissas de Danani e Hintze (2011) e Gentili (2009).

\section{Educação latino-americana na encruzilhada}

Como foi afirmado, anteriormente, há necessidade de se questionar o significado da educação, que emerge, ao usar o conceito de "educação na encruzilhada", do filósofo e pedagogo Jacques Maritain (2008). Esta nomeação é expressa pelo Professor Domingo Rivarola da sede da FLACSO, em Assunção (2017), para refletir sobre a educação paraguaia. Para ampliar essa questão, revisaremos algumas das diretrizes propostas por Maritain (2008), como: a crise da educação; descrição e contexto, erros nas práticas educacionais; os propósitos da educação; os riscos de incorrer em meras instruções; o sentido essencial do treinamento; e os relacionamos com o diagnóstico expresso por professores e pesquisadores de diferentes países irmãos sobre os problemas que seu sistema educacional está passando. Dessa forma, podemos estabelecer pontos de encontro e dissonâncias entre as diferentes experiências locais e ter uma perspectiva mais ampla das encruzilhadas que afetam o sistema educacional latino-americano.

Para explicar como o ensino superior influencia diretamente o desenvolvimento da educação primária, secundária e secundária, o Professor Rivarola (2008) destaca que "há crise na educação, desde o retorno da democracia no Paraguai; e é, por isso, que temos 
aqui uma educação de encruzilhada ainda". Seu depoimento se refere a um de seus artigos publicados na universidade paraguaia, em junho de 2008, no qual extrai cinco pontos decisivos para que o sistema educacional paraguaio tenha uma mudança: o ensino superior; a expansão da demanda; o crescimento da classe média; a reforma educacional; o poder político; e as mudanças culturais.

Essas ideias foram desencadeadoras, porque os participantes dessa discussão apoiaram essas determinações, argumentando que não era apenas um problema do ensino superior paraguaio, mas foi apresentado em todos os níveis do sistema educacional. Um representante da União de educadores do Paraguai argumentou que parte das mudanças foi motivada pela União Nacional (UNE-SN), fundada em 30 de abril de 1992, por meio do Congresso Constitutivo Geral, realizado no Quinto Ykuá Satí. É, assim, que começa o processo de organização do setor de educadores, através das linhas de pensamento dos trabalhadores, que sustentam a Central Nacional dos Trabalhadores (CNT). Por outro lado, um professor de ensino médio argumenta que a matrícula e a designação de escolas como "presença do Estado" são sentidas desde 1992/1994. O professor também destaca que: "Antes não sabíamos o que ensinar, fomos e demos o conteúdo de alguns manuais, que vieram de países da região, como: Uruguai, Chile ou Argentina" (Anônimo, 2017). Além disso, um funcionário do Ministério da Educação e Ciências do Paraguai (MEC) enfatiza que o interesse em reunir indicadores educacionais aparece como uma necessidade, no período de 1992 em diante.

Propõe-se como intervenção nesse debate, a visão da República Argentina, afirmando-se que parece haver uma necessidade tácita de uma reforma educacional sistemática. E, nesta direção, é apresentada a sanção da Lei Federal de Educação 24195, aprovada em abril de 1993.

Em relação à mesa de discussão, realizada na Universidade de Manizales, na cidade de Manizales - Colômbia, no âmbito da II Bienal de Crianças e Jovens, os pesquisadores explicaram que a Colômbia passou por três reformas relacionadas ao sistema educacional. A última foi, em 1991, mas foi incluída na reforma da constituição do país. Os trabalhos de Cifuentes Medina e Camargo Silva (2016) podem ser mencionados, pois especificam que as reformas apresentaram um caminho, que classificaram em três fases: a primeira abrange a independência da Colômbia, entre 1819 e 1902; a segunda começa, em 1903, e vai do século XX até 1990; e a terceira tem como ponto de partida a Constituição de 1991 e chega até hoje.

Cabe mencionar que esse diálogo, na Universidade de Manizales, ocorre no contexto da discussão da educação para a paz. Essa visão foi baseada no acordo de paz promovido em setembro de 2016. Foi, então, que o governo de Juan Manuel Santos 
apresenta as diretrizes estratégicas das políticas públicas nessa perspectiva, em que a educação, em todos os níveis, não era negligenciada.

Dentro deste quadro de trabalho da Universidade de Manizales, também foi proposta uma abordagem sobre a primeira infância e a educação infantil. O sociólogo argentino José Machain (2016) destacou que a educação inicial é de interesse do Estado e da academia, desde a década de 1990, como um movimento mundial. Além disso, o sociólogo apresenta os direitos da criança e enfatiza que ela merece a mais alta prioridade. Pois é, a partir da proteção e do desenvolvimento da criança, que dependem a sobrevivência, a estabilidade e o progresso de todas as nações e, de fato, da civilização humana.

Por fim, o expositor José Eduardo Machain (7 de novembro de 2016) do Observatório Infantil da Cidade de Buenos Aires explicou a importância dos direitos da criança e de seu espaço social como forma de desenvolvimento. $\mathrm{O}$ que mantém ou representa um direito são as garantias institucionais refletidas nas políticas educacionais e no financiamento estatal. Ele recorre a uma citação de Francesco Tonucci ${ }^{3}$, em que se destaca a importância e a urgência de se trabalhar na escola infantil, que nos convida a pensar sobre o que precisamos para que as crianças "transformem a escola" (RADIO SADOP, 2018). A transformação da escola é alcançada com a transformação da cidade, percebendo a cidade das crianças por meio das políticas elaboradas pelo Estado. Assim, podemos interpretar que a transformação da escola não seria superficial ou técnica; ao invés disso, a cidade teria que ser mudada para transformar a escola. A partir daqui, mais elementos emergem, como os objetivos ou metas da educação (MARITAIN, 1943), em que é necessário repensá-los a partir de qual proposta deve ser trabalhada a essência do homem que queremos formar; além de medidas e tecnicismos. Isso destaca o trabalho de Mario Fernandez Enguita (2016), que, desde o conceito da "educação na encruzilhada", apresenta mais elementos que devem ser levados em consideração para o compromisso com a educação e seus desafios. Dentre eles, o autor menciona: professores como espinha dorsal, estudantes, globalização, crises institucionais e desigualdades persistentes.

Nesta seção, procuramos destacar algumas questões sobre as reformas educacionais, educação para a paz na Colômbia e a escola como um local a ser transformado. Nos grupos de discussão, trabalhamos com o método Delphi (ANDEREGG, 1995), em que os especialistas se apresentam como expositores e, em seguida, as propostas apresentadas foram discutidas ${ }^{4}$. Foi possível observar como diferentes atores

\footnotetext{
${ }^{3}$ Francesco TONUCCI, em diálogo con José Machain. Cuestiones de Infancias. Ver: RADIO SADOP, 2018.

${ }^{4}$ Em Fernandez Enguita (2016), há um trabalho com professores, pais e alunos de diferentes áreas e níveis, adicionando o método Delphi para fornecer aspectos a serem levados em consideração de modelos ou projetos educacionais para executar.
} 
(políticos, instituições e o Estado) envolvidos em diferentes parcelas institucionais aparecem na análise de políticas públicas e da educação. O que nos leva a pensar, ainda que brevemente, a respeito do educador e sua posição quanto às políticas educacionais elaboradas pelo governo, assim como em relação à complexidade da educação e suas encruzilhadas.

\section{"O educador essencial" versus o educador essencial}

Citaremos a frase de Amicus Platão, sed magis amica veritas, usada por Fernandez Enguita (2016), para problematizar sobre o papel do educador e seu compromisso político educacional. A tradução desta frase é: "sou amigo de Platão, mas mais amigo sou da verdade", e refere-se ao cuidado do conhecimento técnico, quando se trabalha na educação. Fato observado, nos trabalhos de Maritain (2008), pois o educador deve estar ciente de sua prática educacional e dos propósitos de sua formação. O papel do educador não escapa do campo político (BOURDIEU, 2001), nem de suas relações com o Estado e das políticas públicas implementadas em um projeto político.

Assim, a noção de campo político está sujeita a uma revisão prévia, porque para entendê-lo é necessário interpretar o poder simbólico e as lutas simbólicas que exigem pré-condições para poder se posicionar diante dessas lutas (GUTIERREZ, 2005, p. 9). A noção de campo político, como sua interpretação por meio de representações sociais, requer quatro pontos básicos: a homologação de estruturas cognitivas e estruturas sociais; divisões sociais e esquemas mentais, em que a homologação é simbólica; as estruturas mentais e estruturas sociais cumprem funções políticas; e, finalmente, o enjeu ${ }^{5}$.

Seguindo essa interpretação de Bourdieu, na perspectiva de Alicia Gutiérrez (2005), a primeira etapa é construída por meio do sistema cultural, em que os educadores devem saber que as estruturas sociais influenciam as estruturas cognitivas. Em segundo lugar, o sentido imediato do mundo ou da representação social através de uma imagem ou objeto é o que completa uma comunicação com o sistema de símbolos que ocorre em uma determinada sociedade. Portanto, este segundo estágio não pode ser entendido fora da divisão social e dos esquemas mentais. Terceiro, é a alusão de uma ordem arbitrária através da imposição da legitimação da dominação, também conhecida como weberian theodicea (WEBER, 1944, p. 49), que é chamada de "theodicea" racional por ter uma dominação por meio de conceitos universais”. Portanto, um professor ou educador está relacionado a essas três condições: relação entre as estruturas sociais e as estruturas

\footnotetext{
${ }^{5}$ Traduzido da língua francesa: “em jogo”.
} 
cognitivas; as imagens sobre o ensino que devem ter; e as máximas a serem seguidas universalmente.

É, aqui, que os educadores reparam que a acumulação de capital simbólico implica escolher e agir por meio de funções políticas, que serão centradas na correspondência das estruturas sociais (sociológicas) e nas estruturas mentais (psicológicas), que constituem as relações sociais através da transformação do mundo mediada por uma representação. Enfatiza-se que "sistemas simbólicos não são simplesmente instrumentos de conhecimento, mas também instrumentos de dominação" (GUTIÉRREZ, 2005, p. 377).

Como último ponto, os educadores devem ter um “enjeu”, ou seja, um sentido do jogo que se pretende jogar, uma posição no campo, um compromisso no campo político. É quando pode estar consciente de que sua intervenção na educação é uma contribuição ideológica, pois cada educador é funcional para a produção cultural e é, aí, que ele joga com seu poder simbólico:

[...] sistemas de revestimento, sistemas de classificação, formas simbólicas, representações, constituem um enjeu, um compromisso com as lutas que opõem indivíduos e grupos nas interações rotineiras da vida cotidiana, bem como nos grupos que são empreendidos no campo da política e da produção cultural: ou seja, onde o que é jogado é o poder simbólico. (GUTIÉRREZ, 2005, p. 377).

Assim, o educador essencial deve se considerar um extensionista (Reforma Educativa da Universidade de Córdoba, 1918): um agente de transformação. Esse processo de repensar, no sentido aristotélico, que conjuga a substância e a forma do real, seria contrário ao educador que não consegue rever suas estruturas mentais ou cognitivas; ou seja, quando reafirma que suas representações da política educativa não influenciam suas práticas educacionais. Pois, quando os educadores não entendem que a prática educacional é social, as práticas educacionais passam a corresponder estreitamente aos seus interesses.

Como exemplo, recuperaremos o caso levantado na conversa de Flacso, no Equador, sobre um professor de Educação Física, que obteve estudos de pós-graduação e, ao ensinar Pedagogia geral na universidade, ele sempre negou sua formação inicial. Esse fato é interessante, pois o professor nunca se posicionou politicamente diante da Pedagogia, mas instrumentou tecnicamente os textos adaptando-os aos interesses mutáveis do contexto político da República Argentina - com base no partido de Carlos Saúl Menem, De la Alianza, e, finalmente, até a data de hoje, de Néstor Kirchner e Cristina Fernández de Kirchner. Podemos observar que as práticas do professor de Educação Física se concentram na luta política para atingir "seus objetivos pessoais" (posições políticas, retribuição, favores ou obter uma posição de doutorado). Até os tópicos de pesquisa da universidade foram oportunos, porque ele fez um trabalho técnico, 
que poderia ajudá-lo a assumir uma posição pessoal, como, por exemplo: o professor crítico reflexivo, os rituais da escola e o papel do professor universitário em espaços não presenciais.

Nesta perspectiva, o caso do professor de Educação Física, mencionado anteriormente, reflete como a educação, às vezes, pode ser um meio e não um fim, e a prática educacional uma relação de presentes (BOURDIEU, 2013). Dessa forma, consideramos que é um erro, quando os objetivos da educação não são compreendidos, ou mesmo, quando se considera a educação como se fosse algo apenas utilitário, para o desenvolvimento individual ou para interesses pessoais. Entretanto, é preciso compreender, em especial, a autonomia ou a conquista da liberdade interior que essa tarefa implica (MARITAIN, 1943).

A ideia de um educador politicamente adequado pode ser completada, também, com o que Fernandez Enguita (2016) descreve com o excesso de intelectuais orgânicos ou comprometidos, sem saber para que finalidade ou objetivo. Maritain (1943) acrescenta que, se uma educação sem propósitos essenciais for apresentada, estaremos realizando uma educação técnica que não tem um motivo específico. Paugam (2010) concentra o debate na figura do estudioso e do cidadão. O autor também interpreta, seguindo Raymond Aron, que a especialização "ser professor", geralmente, envolve uma especificidade, mas, para ser professor, é preciso, também, ser capaz de ter uma visão de mundo. Questão que se aplica ao caso dos educadores, que são vistos como estudiosos no campo do ensino, como arquitetos do conhecimento e acadêmicos. Então, os professores não devem perder a consciência humanística (MARITAIN, 2008): uma concepção do mundo e do homem que ajuda a refletir sobre os objetivos últimos da educação. Paugam (2010) destaca uma diferenciação interpretada por Pierre Bourdieu (2012): a reflexão entre estudioso e cidadão. $\mathrm{O}$ estudioso seria representado pela figura do professor, do intelectual ou sábio; e cidadão seria aquele sujeito comprometido com o senso comum e com a construção adequada da identidade coletiva. Os professores assumem que seu compromisso social é ser responsável pela transmissão da cultura, mas são indiferentes a várias políticas públicas e da responsabilidade dos políticos ${ }^{6}$.

O autor se apoia, também, em outra perspectiva de Bourdieu (2012) a respeito do espaço de pontos de vista; já que cada agente, apesar de ocupar uma posição específica, na situação de ensino, pode ter compromissos sociais e políticos. É, por isso, que um conceito-chave de Bourdieu (1984; 2000) é recuperado: o de intelectuais. Para Bourdieu (2000, p. 172): “Os intelectuais têm que ser o que são, produzir e impor sua visão do mundo social". E, mais ainda, enfatiza que: "Não são porta-vozes do universal, menos, ainda, de uma classe universal; entretanto, por razões históricas, têm frequentemente

\footnotetext{
${ }^{6}$ Paugam (2010), ao definir o Estado, apresenta essa troca entre cidadão e intelectual.
} 
interesse no universal" (grifos do autor; tradução livre). Para nós, quando o pesquisador e /ou educador se compromete com uma ação social que está exercendo, poderemos considerá-lo como um "intelectual", na contramão daquele professor que usa técnicas pedagógicas neutras, e que se enquadra em uma linha de obediência e especialidade.

Outro problema, que pode estar relacionado aos educadores, é o dos professores que estão longe do debate político; entretanto, ao mesmo tempo, muitos professores são vistos como figuras públicas nos principais centros de discussão política. Assim, Paugam (2010) pretende examinar o caso específico do sociólogo, interpretando Pierre Bourdieu (2012) e Aron, relacionados à política, como o sociólogo, que “[...] precisa de uma crítica epistemológica plenamente justificada em uma sociologia da sociologia" (PAUGAM, 2010, p. 347). De fato, poderíamos dizer que educadores como sociólogos devem poder criticar seus conhecimentos; ou seja, realizar uma educação para educar e, ao mesmo tempo, participar ativamente de políticas públicas, cumprindo, assim, sua dupla identidade: a de cidadãos e estudiosos.

\section{Repensando a encruzilhada (Discussão)}

Assim, a "educação na encruzilhada" pode ser interpretada pelas mudanças que determinam o sistema educacional, mas sem perder de vista a proposta de Maritain (2008), vendo o sentido do treinamento de técnicos ou de reformas que levarão a mudanças culturais. Além do compromisso com a educação (ENGUITA, 2016), o desafio de entender as circunstâncias históricas de nossos países latino-americanos, observando suas diferenças estruturais e materiais, parece-nos que são pontos fundamentais a serem revisados.

Desde o início das trocas, nos diferentes diálogos, era problemático definir o conceito de Estado. Tivemos que recorrer a definições de Estado por meio de Oszlak (1982), Grassi (2008) e Bourdieu (2013), em alguns casos para concordar. Essas definições propostas para a leitura não são inocentes, porque procuram envolver agentes educacionais (sindicalistas, professores e técnicos) com uma noção de Estado, em que o educador tem uma responsabilidade cívica. Por outro lado, essa noção de Estado leva ao conceito de estado capitalista (DANANI, 1996), e como as políticas educacionais podem proteger ou desproteger (DANANI; HINTZE, 2011) a comunidade educativa.

Por outro lado, as reformas educacionais expostas nas mesas de trabalho e nos debates, mencionados nas contribuições do Professor Rivarola (2017), na sede da Flacso Asunción, coincidem com a visão de professores e pesquisadores de vários países da América Latina, em que foram observadas as reformas educacionais ocorridas nos anos de 1991 a 1994. Isso, mais tarde, levou a várias críticas e reflexões. 
Todavia, nos tempos atuais, podemos pensar que essas mudanças não têm origem na própria reforma, pois estaríamos contradizendo as propostas de Maritain (2008) a respeito de priorizar tecnicismos sobre os objetivos da educação. Mais uma vez, observamos que, nos diálogos, quando se identificam problemas, os mesmos aparecem como temas comuns, como reformas educacionais, indicadores educacionais, educação infantil, poder político e políticas educacionais ou presença do Estado. Situações transversais à educação, que poderiam ser interpretadas como "encruzilhadas". As reformas educacionais, dos anos 1990, na Colômbia, Equador, Argentina e Paraguai, têm, em comum, o caráter jurídico-administrativo, em que a hierarquia legal é executada, forçando os agentes educacionais a implementarem políticas, que levem a repensar o Estado, o público e os sentidos de cidadania.

O educador como um agente educacional essencial deve revisar a intelectualidade orgânica e não contribuir para sistemas desprotetores. Seguindo Fernández Enguita (2016), esses intelectuais orgânicos são, muitas vezes, oportunistas e não comprometidos; pois, trata-se de educadores e/ou técnicos, que se juntam a projetos políticos desprotegidos, pois não atendem às necessidades das comunidades, porque têm uma percepção generalizada das mudanças que querem implementar. Por isso, consideramos necessário que o educador possa se instrumentalizar para assumir condições de rever o seu sistema simbólico, de capital simbólico e refletir sobre suas ações de intervenção no campo político (BOURDIEU, 2001). Esse processo deve ser inspecionado em quatro aspectos, para que um educador saiba que suas estruturas cognitivas, esquemas mentais, representações sociais operam em conjunto com as estruturas sociais (GUTIERREZ, 2005). Caso contrário, os agentes educacionais podem sofrer uma ataraxia (VILLARREAL, 2018), deixando um educador vivendo fora do jogo e negando sistematicamente estar nele, ou ainda, estar enjeu.

A "educação na encruzilhada" visa não apenas a buscar caminhos ou possibilidades transversais para a educação, mas também conceder a possibilidade de que os agentes educacionais envolvidos na transmissão da cultura possam realizar uma crítica epistemológica baseada na educação da educação: uma educação com foco no exame da noção de Estado, bem como em uma visão de mundo. Se, a partir das políticas públicas, o educador for favorecido a agir de acordo com seu enjeu, é possível inferir que o mesmo estará se desenvolvendo como um educador consciente, que se percebe cidadão e estudioso.

Ficará, para outra análise, o desenvolvimento de um estudo mais detalhado dessas encruzilhadas, para que possamos traçar novas rotas que incluam outras experiências educacionais latino-americanas, como: Brasil, Chile, Uruguai, Venezuela, Nicarágua, Peru, Costa Rica, México, entre outras. Certamente, os temas ou caminhos serão mais amplos do que aqueles apresentados, brevemente, nas mesas de trabalho e discussões, e 
poderão construir um perfil mais crítico dos professores, como participantes ativos das políticas públicas.

Por outro lado, e como proposta de investigação futura, poderia ser enquadrado o estudo das reformas educacionais na América Latina dos anos 2000 - 2020, enfatizando o olhar nas políticas públicas, que visam a um objetivo de inclusão, integração e equidade, a fim de observar como os educadores se posicionam contra cada conteúdo proposto pelas novas reformas educacionais e as demandas contextuais desafiadoras colocadas pelo novo milênio. De fato, este breve texto busca desafiar os diferentes atores da educação, reavaliando o papel político dessa árdua tarefa, que implica ser transmissora de cultura em um mundo profundamente desigual.

\section{Referências}

ANDER-EGG, E. Técnicas de recolección social. Buenos Aires, Editorial LUMEN, 1995.

BALLART, X.; RAMIÓ, C. Ciencia de la administración. Valencia, Tirant lo Blanch, 2000.

BOURDIEU, P. Questions de sociologie. Paris, Les Éditions de Minuit, 1984.

BOURDIEU, P. Razones Prácticas. Barcelona, Editorial Anagrama. 1997.

BOURDIEU, P. Intelectuales, política y poder. Buenos Aires, Editorial Universitaria de Buenos Aires. 2000.

BOURDIEU, P. El campo político. La Paz, Plural Editores, 2001.

BOURDIEU, P. A Miséria do mundo. 9 ed. Petrópolis, Vozes, 2012.

BOURDIEU, P. El sentido práctico. Buenos Aires, Editorial Siglo XXI SA, 2013.

DANANI, C. Algunas precisiones sobre la política social como campo de estudio y la noción de población objeto. In: Políticas Sociales: contribución al debate teóricometodológico. Buenos Aires, UBA, 1996. (Colección CEA-CBC nº 11)

DANANI, C.; HINTZE, S. Protecciones y desprotecciones: la seguridad social en la Argentina 1990-2010. Bueno Aires, Ediciones UNGS, 2011.

FELDFEBER, M. La construcción del derecho a la educación: reflexiones, horizontes y perspectivas. Revista Educação e Filosofia. Dossiê "A Educação pública como direito: desafios às políticas governamentais na América Latina”. Uberlândia, v. 28, n. especial, p.139-153, 2014. Disponível em: http://www.seer.ufu.br/index.php/EducacaoFilosofia/ article/viewFile/24607/1536. Acesso em: 10 jun 2020. 
FERNANDEZ ENGUITA, M. La educación en la encrucijada. Madrid, Fundación Santillana. 2016.

GENTILI, P. Marchas y contramarchas: El derecho a la educación y las dinámicas de exclusión incluyente en América Latina (a sesenta años de la Declaración Universal de los Derechos Humanos). Revista Iberoamericana de Educación, n. 49, p. 19-57. 2009.

GIDDENS, A. La constitución de la sociedad. Buenos Aires, Amorrortu, 1995.

GÓMEZ MENDOZA, M. A. Análisis de contenido cualitativo y cuantitativo: Definición, clasificación y metodología. Revista de Ciencias Humanas - UTP, n. 20. Colombia, Pereira, p. 30 - 42, 2000.

GRASSI, E. Políticas y problemas sociales en la sociedad neoliberal: la otra década infame. Buenos Aires, Espacio Editorial, 2008.

GUTIERREZ, A. Poder y representaciones: elementos para la construcción. Revista Complutense de Educación, v. XVI, n. 2, Revista Complutense de Educación. Madrid, v. 16, n. 2, p. 373-385, jun. 2005.

KRAFT, M., FURLONG, S. Public Policy: Politics, Analysis and Alternatives, 2nd ed., Washington, DC, CQ Press, 2006

MARITAIN, J. La educación en la encrucijada. Madrid, Editorial La Palabra, 2008.

MARITAIN, J. Los fines de la Educación: primera de cuatro conferencias dictadas por Maritain. New York, Universidad de Yale, 1943.

OCAMPO, J. A. Reconstruir el futuro. Globalización, desarrollo y democracia en América Latina. Bogotá, Editorial Norma, 2004.

OSZLAK, O. Reflexiones sobre la formación del estado y la construcción de la sociedad argentina. Desarrollo Económico Revista de Ciencias Sociales, Buenos Aires, v. XXI, p. 1-18, enero-marzo, 1982.

PAUGAM, S. A pesquisa sociológica. Petrópolis, Vozes, 2010.

RADIOSADOP. Cuestiones de infancia. Programa \#23 - FRANCESCO TONUCCI / Infancia, Participación, Ciudad y Escuela. (22 de Diciembre 2018). RadioSADOP. Recuperado en: https://www.cuestionesdeinfancias.com/2018/10/programa-23francesco-tonucci-infancia.html\#more.

RIVAROLA, D. La universidad paraguaya, hoy. Revista Avaliação, Campinas, vol. XIII, n. 2. p. 533-578, Julio del 2008.

SAMPIERI HERNÁNDEZ, R., FERNANDEZ CALLADO, C., BAPTISTA LUCIO, P. Metodología de la Investigación. México, Editorial Mc Graw Hill., 2010. 
SOUSA DE SANTOS, B. El Estado, el derecho y la cuestión urbana. In: NEUFELD, M. R. et al. (Org.). Antropología social y política. Hegemonía y poder: el mundo en movimiento. Buenos Aires, Editorial Eudeba, 1998.

VILLARREAL, A. Las representaciones sociales acerca de la Asignación Universal por hijo (AUH) de los agentes escolares, las familias y su incidencia en los procesos socio educativos. Actas de las VI Jornadas sobre Etnografías y Procesos Educativos. Universidad de Buenos Aires. Programa de Antropología Social. Instituto de Desarrollo Económico y Social. Buenos Aires, 2016.

VILLARREAL, A. Las representaciones sociales acerca de la Asignación Universal por hijo (AUH) de los agentes educativos, las familias y su incidencia en los procesos socio educativos. Tesis doctoral. Ciudad de Córdoba, Repositorio, Universidad Nacional de Córdoba, Secretaría de Posgrado, 2018.

VIEYTES, R. Metodología de la Investigación en Organizaciones, Mercado y Sociedad, Epistemología y Técnicas. Buenos Aires, Editorial de las Ciencias, 2004.

WEBER, M. Economía y sociedad: esbozo de sociología comprensiva. México, Fondo de Cultura Económica., 1944

$* * *$

Recebido em: 21 mar. 2020.

Aprovado em: 11 jun. 2020.

\footnotetext{
*Agustín Villarreal Doutor em Ciências da Educação (UNC). Pós-doutorado em Ciências Humanas e Sociais (UBA - Em curso). Magister em Políticas Sociais (UNaM). Especialista em Políticas Socioeducativas. Lic. em Educação. Professor Sup. em Artes. Professor de Filosofia. Universidade onde leciona: Professor em Intr. em Sociologia, y Pedagogia General, Gestão Cultural, Talher de Música Latino-americana (UNaM), Analises y Amônia (ISPAO), e Didática General (ISFPF). Bec Tipo I (IESyH - CONICET). Diretor do grupo de pesquisa (Inst. Paulo Freire de Capioví №1117).

E-mail: angusvillarreal@hotmail.com

http://orcid.org/ 0000-0002-7648-6583
} 